\section{Spring Influences on Olive Flowering and Threshold Temperatures Related to Reproductive Structure Formation}

\author{
Fabio Orlandi', Carlo Sgromo, Tommaso Bonofiglio, Luigia Ruga, \\ Bruno Romano, and Marco Fornaciari \\ Department of Applied Biology, University of Perugia, Borgo XX giugno, 74, \\ 06121 Perugia, Italy
}

Additional index words. olive cultivars, flowering, pollen, thermal requirements

\begin{abstract}
Several bioclimatic studies have been developed over recent years considering temperature trends and their influence on vegetative and reproductive phenomena during plant growth. In the applied aerobiology laboratory of Perugia University, various studies of olive (Olea europaea L.) flowering and its relationship with climatic variables have been conducted. Since 1999, a flowering monitoring network in centralsouthern Italy has been working to track the biological phenomena over the years, the possible differences between the monitoring stations, and the relationships with climate. Olive flowering was monitored in $\mathbf{1 5}$ monitoring stations located in four Italian regions (Campania, Calabria, Puglia, and Sicily) representing $\approx 90 \%$ of national olive territories. The flowering phenophase was studied through pollen emission monitoring, making use of scientific instruments that capture defined volumes of atmosphere and allow us to ascertain the pollen emission trends, thereby determining daily average pollen concentrations (pollen grains $/ \mathrm{m}^{3}$ ). The combined analysis of pollen monitoring and meteorological data permitted identifying various groups of stations characterized by the fact that better relationships between reproductive structure development and growing degree-days are obtained with different spring threshold temperatures (low 7 to $10^{\circ} \mathrm{C}$ or high 11 to $14^{\circ} \mathrm{C}$ ). Moreover, the study permitted demonstrating particular meteorological and biological behaviors, providing useful information about plant-climate relationships in a species of economic interest affected by interincompatibility.
\end{abstract}

The present study considers the relationships between temperature trends and the reproductive development of fruit trees, taking its place within the research field of bioclimatic studies, which has improved considerably in recent years with a major contribution by a number of scientists (Bonhomme, 2000; Galán et al., 2001). In reality, several studies were conducted to determine the relationships between climate and flowering phenomena in different species (Pellizzaro et al., 1996) to highlight in particular the influence of temperature requirements and consequent reproductive structures maturation/pollen emission phases (Alcalá and Barranco, 1992; Fornaciari et al., 2005; Orlandi et al., 2005a). The study of pollen flows through aerobiology is a promising approach toward studying the phenology of the entire communities, although it is taxonomically limited in scope (dominated by trees) and resolution (identified at the genus or family level), and there is uncertainty about the degree of long-distance pollen transport (Estrella et al., 2006). On the other hand, airborne pollen data are the only source of information on spring phenology on a regional scale, providing regional response and limiting the disturbance caused by microenviron-

Received for publication 10 Feb. 2010. Accepted for publication 11 May 2010.

${ }^{1}$ To whom reprint requests should be addressed; e-mail fabor@unipg.it. mental variability. Airborne pollen data reflect reproductive phenology and can be used efficiently to track the impact of global climate change on plants. Recently, some studies have been conducted to investigate the relationships between airborne pollen of anemophilous species and climatic trends using pollen monitoring as reproductive phenological data (Emberlin et al., 2007; Orlandi et al., 2005b; Osborne et al., 2000).

The present study, conducted within a Mediterranean area over an 11-year period (1999 to 2009), studied the potential relationships between spring temperature expressed as temperature summations [growing degreedays (GDD)] and flowering dates interpreted through pollen emission in a typical Mediterranean species (Olea europaea) to evaluate the best-adapted olive cultivars in the different olive-growing areas and interpret the biological responses of cultivated plants in relation to the current climate changes.

The flowering phase of the investigated species was studied in some of the principal olive-growing areas in four southern Italian regions (Campania, Calabria, Puglia, and Sicily), which represent $\approx 90 \%$ of national olive-growing territories.

Flowering trends were determined on the basis of pollen emission in the atmosphere monitored through a technique that allows obtaining average daily pollen concentrations. The principal aim of this type of research is to interpret the development of reproductive structures of cultivated plants in relation to the principal meteorological variables so as to realize flowering maps. In particular, these analyses could be very useful in relation to species of economic interest such as the olive affected by auto- and interincompatibility among its different cultivars.

\section{Materials and Methods}

Study area. During the study period (1999 to 2009), olive pollen emission was investigated continually and directly in the olive orchards, from April to June of each year, with the use of volumetric monitoring samplers (pollen traps) powered directly in the field with solar panels and electric supplies (Fig. 1). The daily average pollen concentrations (pollen grains $/ \mathrm{m}^{3}$ of air) were elaborated through laboratory techniques considering the pollen captured by the instruments in the 15 olive-growing areas monitored (Fornaciari et al., 2000; Orlandi et al., 2009). The areas considered were selected on the basis of their representativeness within the varied Italian genetic heritage characterized by a large number of olive cultivars (Table 1).

Methodology. The analysis of daily olive pollen emission behaviors in each year and area permitted reconstructing the different emission trends as proxies of flowering phenomenon. In each geographic area, the elaboration of pollen emission trends permitted spotlighting the exact days when pollen flows appeared in the atmosphere, clearly manifesting the start of the flowering phase for the orchards around the pollen traps. These evaluations allowed determining the start of flowering, defined as the day in which one pollen grain $/ \mathrm{m}^{3}$ was recorded whenever five subsequent days contained one or more pollen grains $/ \mathrm{m}^{3}$, and maximum flowering (MF) defined as the day of maximum pollen concentration as well as the end of flowering defined as the last day with pollen concentration.

Once the flowering dates were calculated for each of the 15 areas, the temperature requirements expressed in GDD were evaluated to analyze their relationships with reproductive structure development.

The daily GDD were obtained with the use of seven calculation methods: single triangle, single sine, Allen, De Wit, Wilkerson, Parton, and Cesaraccio. Moreover, the GDD values were calculated using 13 different threshold temperatures (TT) from 3 to $15{ }^{\circ} \mathrm{C}$.

The meteorological data: minimum, maximum temperatures $\left({ }^{\circ} \mathrm{C}\right)$, and rain $(\mathrm{mm})$, were surveyed from 15 meteorological stations of the national agrometeorological network located near the monitored olive orchards. Then, for each olive-growing area, the GDD summations (calculated with different methods and threshold temperatures) were calculated considering the first of January as the starting date and as final dates the MF days.

Statistical analysis. Based on the GDD amount values obtained year by year, the variability in degree days was calculated 
using the root square mean error (RSME) method (Snyder et al., 1999). This analysis permitted characterizing the different monitoring areas in terms of GDD calculation method and TT. The parameters that minimized the differences of GDD summations during the study years were considered as the best method and temperature for each area considered. In particular, the best TT was considered as that temperature above which the olive flowering structures are unconstrained to develop achieving maturity and emitting pollen grains in the atmosphere.

Finally, a trend analysis was realized considering the flowering dates from 1999 to 2009 in each monitoring area. The presence of positive or negative trends (delayed or early flowering) over the years was investigated with the Mann-Kendall test. The trend presence was evaluated by the $\mathrm{Z}$ coefficient (positive value-increasing trend; negative-decreasing). Moreover, this type of analysis was also conducted for temperature amounts obtained in each area so as to also highlight potential meteorological variations over the years. To estimate the true slope of an existing trend (as change per year), the Sen's nonparametric method was used (Sirois, 1998). For the four tested significance levels, the following symbols are used in the template: $* * *$ if trend at $\alpha=0.001$ level of significance; $* *$ if trend at $\alpha=0.01$ level of significance; $*$ if trend at $\alpha=0.05$ level of significance; and + if trend at $\alpha=0.1$ level of significance. All trends are calculated using an Excel template MAKESENS Version 1.0 (Microsoft Inc., Redmond, WA).

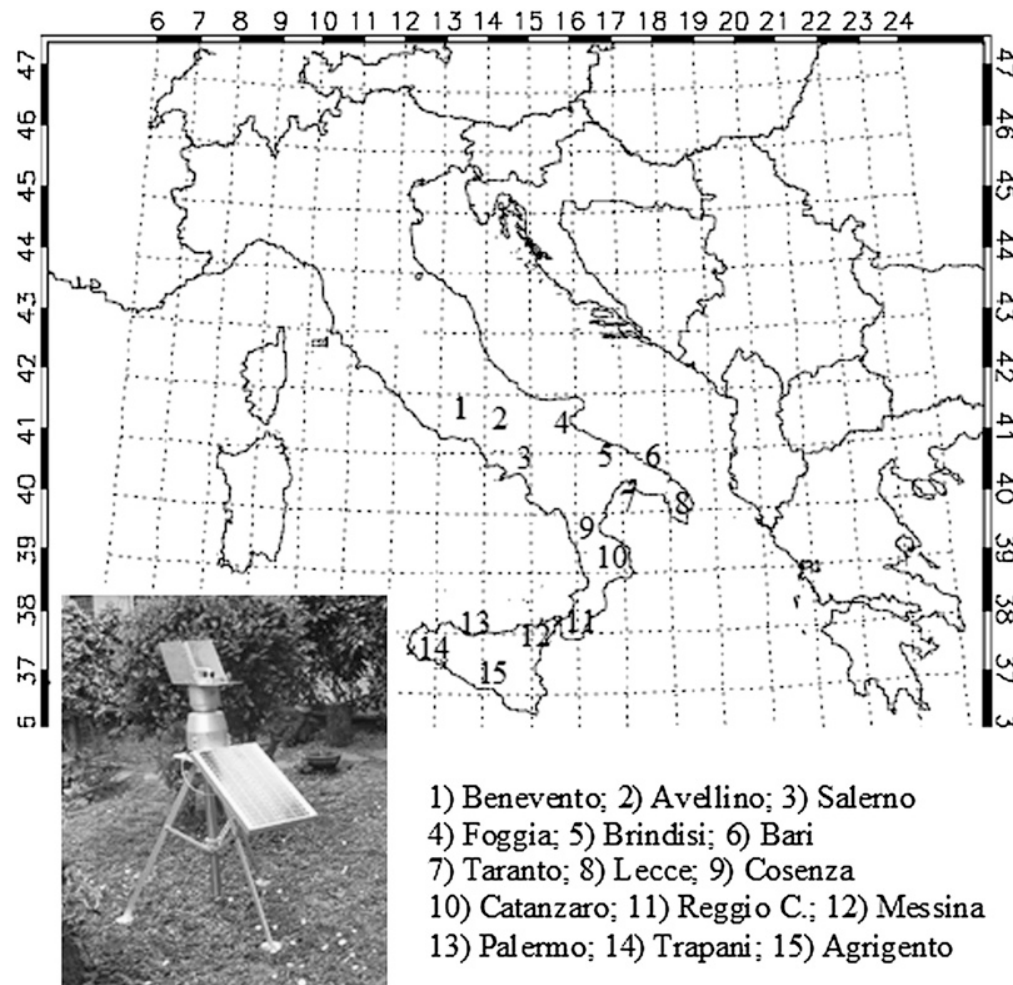

Fig. 1. Self-powered volumetric pollen trap (Lanzoni VPPS 2010) located in the 15 monitoring areas of south Italy (1-3 Campania region; 4-8 Puglia region; 9-11 Calabria region; 12-15 Sicily region).

\section{Results and Discussion}

The analysis of yearly pollen emission trends permitted ascertaining that in practice, the greatest part of pollen flows was recorded during 1 week in each olive-growing area. The pollen traps started to record olive pollen grains in southern Italy from the first days of May during all of the years of the study, whereas they finished in the last days of the same month.

In each of the monitoring areas considered, very close relationships were recorded between temperature amounts useful for reproductive structure development and the actual MF dates. In some cases, particular problems were noted for calculating variability values (RSME) with the use of very low temperatures (from 3 to $4.5{ }^{\circ} \mathrm{C}$ ) as $\mathrm{TT}$, because in particularly warm areas such as Messina and Reggio Calabria, the daily temperatures never were below those TT for long periods. In this manner, the GDD values remained constant so that it was not possible to highlight variability over the years.

In correspondence with the minimum RSME values calculated for each monitoring station, the threshold temperatures that minimize variability of yearly GDD amounts were identified, indicating for each geographic area the temperature above which "useful thermal values" are cumulated during the study years (Fig. 2). The same evaluation was conducted to define the better GDD calculation methods; in this case, the result analysis indicated that the daily GDD obtained with the "sine" method permitted minimizing the variability in the yearly GDD amounts. The presence of positive or negative trends (late or early flowering) in the study years was analyzed with the Mann-Kendall test through which the coefficient $\mathrm{Z}$ shows a positive value in correspondence with an increasing trend and a negative value with a decreasing trend (Table 2). The significance levels obtained in each monitoring area were satisfactory with the highest value in correspondence with Reggio Calabria demonstrating the presence of clear thermal and flowering tendencies.

The biological interpretation of the trend analysis results was realized with the assumption that the temperature requirements of the olive plants monitored were not

Table 1. Olive monitoring areas in south Italy and principal olive cultivars.

\begin{tabular}{|c|c|c|c|c|c|c|}
\hline Regions & Provincies & Commons & Long. & Lat. & Alt. (m) & Olive cultivars \\
\hline \multirow[t]{3}{*}{ Sicily } & Agrigento & Ribera & $13^{\circ} 31^{\prime}$ & $37^{\circ} 30^{\prime}$ & 158 & Biancolilla, Cerasuola \\
\hline & Palermo & Termini Imerese & $13^{\circ} 06^{\prime}$ & $38^{\circ} 11^{\prime}$ & 21 & Ogliarola messinese, Biancolilla \\
\hline & Trapani & Castelvetrano & $12^{\circ} 30^{\prime}$ & $37^{\circ} 55^{\prime}$ & 7 & Nocellara del Belice, Giarraffa \\
\hline \multirow[t]{4}{*}{ Puglia } & Bari & Bitonto & $16^{\circ} 38^{\prime}$ & $41^{\circ} 03^{\prime}$ & 191 & Coratina, Ogliarola Barese \\
\hline & Brindisi & Pezze di Greco & $17^{\circ} 01^{\prime}$ & $40^{\circ} 55^{\prime}$ & 230 & Ogliarola salentina, Coratina \\
\hline & Foggia & San Servero & $15^{\circ} 33^{\prime}$ & $41^{\circ} 26^{\prime}$ & 57 & Peranzana, Ogliarola \\
\hline & Lecce & Squinzano & $18^{\circ} 21^{\prime}$ & $39^{\circ} 49^{\prime}$ & 104 & Cellina di Nardo, Ogliarola salentina \\
\hline \multirow[t]{3}{*}{ Calabria } & Catanzaro & Staletti & $16^{\circ} 16^{\prime}$ & $38^{\circ} 58^{\prime}$ & 216 & Carolea, Frantoio, Ottobratica \\
\hline & Cosenza & Spezzano Alb. & $16^{\circ} 27^{\prime}$ & $39^{\circ} 44^{\prime}$ & 10 & Cassanese, Carolea \\
\hline & Reggio C. & Palmi & $15^{\circ} 39^{\prime}$ & $38^{\circ} 04^{\prime}$ & 11 & Ottobratica, Cassanese \\
\hline \multirow[t]{3}{*}{ Campania } & Avellino & Ariano Irpino & $14^{\circ} 40^{\prime}$ & $41^{\circ} 07^{\prime}$ & 136 & Ravece, Olivella \\
\hline & Benevento & Solopaca & $14^{\circ} 67^{\prime}$ & $41^{\circ} 43^{\prime}$ & 178 & Ortolana, Ortice \\
\hline & Salerno & Campagna & $14^{\circ} 52^{\prime}$ & $40^{\circ} 37^{\prime}$ & 29 & Rotondella, Carpellese, Frantoio \\
\hline
\end{tabular}




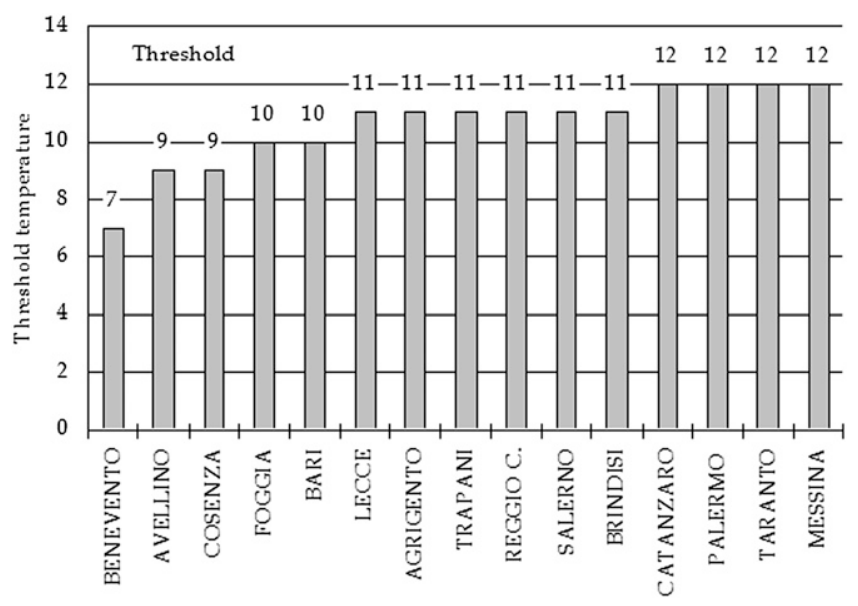

Fig. 2. Threshold temperatures used for growing degree-day (GDD) calculation in every olive monitoring area to minimize thermal amounts variability during the study period (1999-2009).

Table 2. Trend analysis test (Mann-Kendall test).

\begin{tabular}{lrrr}
\hline & \multicolumn{2}{c}{ Flowering dates } & GDD amounts \\
\cline { 2 - 4 } Time series & \multicolumn{2}{c}{ Z coefficients } & Significance levels \\
\hline Benevento & 0.00 & -4.40 & $*$ \\
Foggia & 0.00 & 0.00 & $*$ \\
Avellino & 0.99 & 1.87 & + \\
Bari & -0.15 & 1.40 & $*$ \\
Cosenza & -0.63 & -0.47 & $*$ \\
Lecce & -0.09 & 1.87 & $*$ \\
Agrigento & -0.07 & 0.00 & $*$ \\
Trapani & 0.09 & -0.93 & + \\
Reggio C. & 2.16 & 2.02 & + \\
Salerno & 0.27 & 1.09 & $*$ \\
Brindisi & 1.72 & 2.34 & + \\
Catanzaro & -0.45 & -1.40 & + \\
Palermo & 2.15 & 0.00 & $*$ \\
Taranto & 2.42 & 1.25 & + \\
Messina & 1.43 & 2.34 & + \\
\hline
\end{tabular}

GDD = growing degree-days.

significantly different during the study period. The trend analysis permitted identifying six different scenarios in the various study areas derived by the contemporary interpretation of GDD amounts and flowering behaviors (full flowering as days from 1 Jan.) during the study period. In Figure 3 , the different scenarios are shown with the linear regression equations of the two variables evidencing their trend significance. The first scenario is characterized by a flowering delay, which determines a higher thermal amount (in accordance with the preceding assumption) in some monitoring areas (Fig. 3A), whereas the second is marked by early flowering followed consequently by a lower thermal amount in other areas (Fig. 3B). These first two behaviors were defined as "phenotypic plasticity not induced by temperature variations," Because other meteorological variable variations during the pre-flowering period probably have to be considered as the principal causes of flowering date changes (our attention was consequently directed toward rainfall amounts). In yet other areas, a third and a fourth scenario (Fig. 3C-D) were observed in which the flowering dates in practice did not present a clear trend, whereas the GDD amounts calculated in correspon- dence of them changed both with positive (monitoring area of Bari) and negative trends (Trapani area). This particular phenomenon was identified with the term "phenotypic rigidity." In the monitoring areas where this phenomenon was recorded (inside the provinces of Benevento, Salerno, Bari, Lecce, and Trapani), specific olive cultivars did not significantly modify their flowering dates (as demonstrated by trend analysis), even in the presence of thermal amount variations. A fifth case presented itself only in one station (Palermo area; Fig. 3E), in which the temperature summation trends clearly induced phenological date modifications ("phenotypic plasticity" induced by thermal variations). Finally, the last case, characterized by no trend presence, was recorded in the monitoring areas of Foggia and Agrigento, where both thermal and flowering behaviors demonstrated fairly constant values over the study years (Fig. 3F).

The case in which "phenotypic plasticity" (early or late flowering) was not induced by spring thermal variations prompted an indepth meteorological analysis, which demonstrated the importance of rainfall amounts during the pre-flowering weeks in the matu- ration of reproductive structures. In reality, the negative pre-flowering rain amount trends evidenced a particular statistical significance, inducing a delay in olive flower anthesis; instead, the flowering advance was not justified by a clear rainfall trend (Fig. 4). Most likely, the drop in rainfall during the study period induced a stressful situation for the cultivated plants (crop water stress in the first reproductive phases also), which reacted by delaying flower structure development, whereas an increase in rainfall patterns had no influence on the phenomenon, showing that in the study areas, the usual quantity of rain during spring is sufficient for determining regular flower structure formation.

A particular biometeorological consideration can be outlined for three scenarios, the third and fourth showing the phenomenon of phenotypic rigidity and the fifth showing "phenotypic plasticity induced by thermal variations." These three scenarios present a significant capacity to highlight meteorological tendencies in the areas of study. In particular, the third and fourth scenarios permit noting that in correspondence of similar phenological dates over the years, higher or lower temperature amounts are recorded in relation to warming or chilling meteorological trends in progress. Moreover, the fifth scenario demonstrates how similar temperature summations are recorded increasingly earlier or later in accordance with warming or cooling meteorological trends present in the study territories. In Table 3, the monitoring areas representing the different scenarios are shown and then a summary of the different olive cultivars behaviors is presented. The olive cultivars of the monitoring areas affected by phenotypic rigidity were those with the fewest problems in terms of flower fertility, considering that potential climatic changes will have little influence on their flowering periods and consequently on the overlaps of compatible olive cultivars flowering. Moreover, in the olive-growing area characterized by phenotypic plasticity induced by temperature variations, the cultivars planted are the only ones that present total (Ogliarola Messinese) or partial (Biancolilla) self-compatibility (Fontanazza and Baldoni, 1990; Jacoboni and Fontanazza, 1981), limiting their need to correspond with the flowering periods of other cultivars. On the other hand, all the cultivars of olive-growing areas affected by phenotypic plasticity not induced by temperature variations presented auto-incompatibility (OLEA Databases, 2007), inducing the consideration of water volumes also in pre-flowering to regularize the flowering onset dates and to limit the risk that anthesis phenomena of potential pollinator and pollinated cultivars may be out of phase.

\section{Conclusions}

The analysis of the results obtained by combining pollen monitoring with bioclimatic evaluations evidenced first the presence of a group of monitoring stations for which the better relationships between 


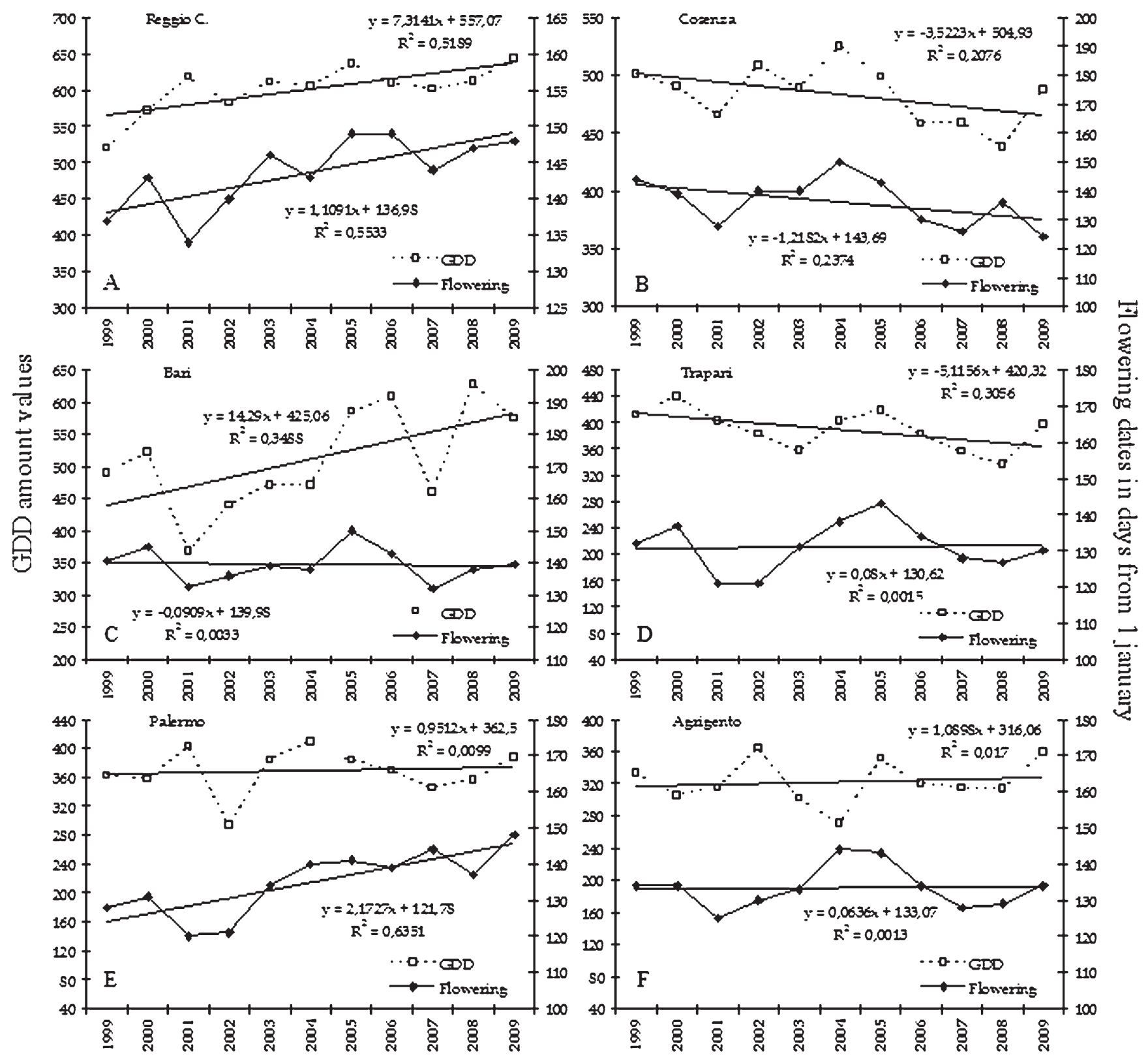

Fig. 3. (A-F) The six different scenarios of growing degree-day (GDD) amounts and olive flowering trends are represented through the more significant monitoring areas for each one of them (Reggio C., Cosenza, Bari, Trapani, Palermo, and Agrigento).

reproductive structure developments and GDD summations were obtained with the use of low threshold temperatures of 7 to 9 ${ }^{\circ} \mathrm{C}$. This group constituted three monitoring areas (Benevento, Avellino, and Cosenza) located in the proximity of the Italian Apennine mountain chain and representing the colder climatic zones among the study areas. In actuality, in these coldest areas, flower structures start to satisfy thermal requirements for developing reproductive buds already at low temperatures, also considering that the breaking dormancy phenomenon is anticipated in these contexts.

Other two groups of monitoring stations can be determined in consideration of the climatic characteristics, because the better threshold temperatures for these latter were those included in the range of 11 to $14^{\circ} \mathrm{C}$. The geographic areas of these two groups were different and separated by the mountain chain previously cited (south Apennine Mountains) with climatic conditions more influenced by the presence of the sea. From this perspective, the TT values reflect the different local meteorological trends but are deeply influenced by the phenomenon of plant adaptation to the microclimates of the different areas.

Until now, rainfall was essentially related to the pollen quantity emission in olive agroaerobiological studies (Recio et al., 1996; Rodríguez-Rajo et al., 2004) and not to the flowering dates. In the present study, a reduction in rainfall was also related to a delay in flowering, and these findings are in accordance with the following relationships observed in other olive studies: rain reductionpollen emission volume reduction (Candau et al., 1998) and flowering delay-pollen quantity reduction (Rodríguez-Rajo et al., 2004). Moreover, the complex relationships between rain reduction-flowering delay-low pollen quantity can be agronomically improved by linking the low final olive yield evidenced in past studies to the low pollen emission (Fornaciari et al., 2005; Galán et al., 2004).

The different sensitivity to the climatic conditions prompts verifying all of the agronomic aspects of olive cultivation, considering in particular the behaviors of the cultivars considered as pollinators in relation to the pollinated ones. In reality, the synchronous flowering periods in a geographic area can be out of synchrony both with the translation of olive-growing area and in the presence of climatic changes. This consideration has 


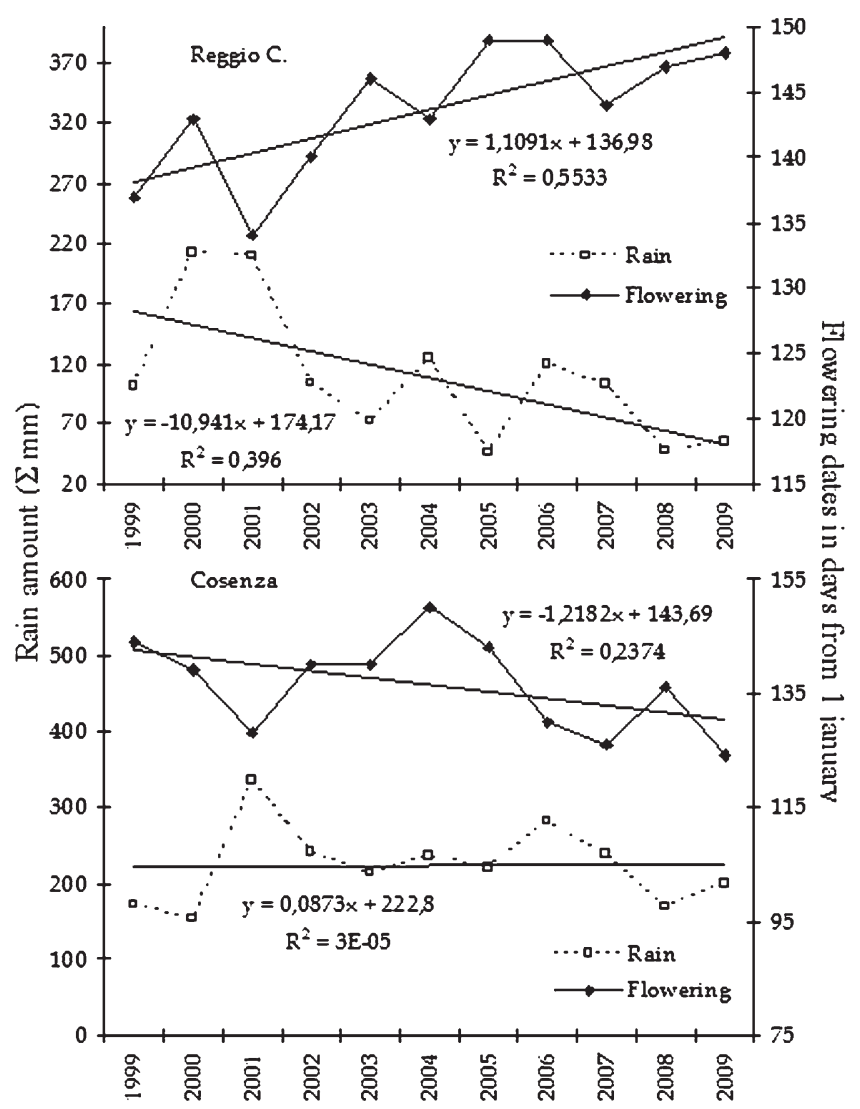

Fig. 4. Relationships between rain amounts and flowering dates in two monitoring areas included in the scenario of "phenotypic plasticity not induced by spring thermal variations."

Table 3. Riepilogative behaviors of different olive cultivars in the study areas.

\begin{tabular}{llll}
\hline & Provincies & \multicolumn{1}{c}{ Commons } & \multicolumn{1}{c}{ Olive cultivars } \\
\hline Scenario $\mathrm{I}^{\mathrm{z}}$ & Avellino & Ariano Irpino & Ravece, Olivella \\
& Reggio C. & Palmi & Ottobratica, Cassanese \\
& Brindisi & Pezze di Greco & Ogliarola salentina, Coratina \\
& Taranto & Avetrana & Cellina di Nardo, Coratina \\
& Messina & Ficarra & Minuta, Verdello \\
Scenario $\mathrm{II}^{\mathrm{z}}$ & Cosenza & Spezzano Alb. & Cassanese, Carolea \\
& Catanzaro & Staletti & Carolea, Frantoio, Ottobratica \\
Scenario III & Bari & Bitonto & Coratina, Ogliarola Barese \\
& Lecce & Squinzano & Cellina di Nardo, Ogliarola salentina \\
& Salerno & Campagna & Rotondella, Carpellese, Frantoio \\
Scenario $\mathrm{IV}^{\mathrm{y}}$ & Benevento & Solopaca & Ortolana, Ortice \\
& Trapani & Castelvetrano & Nocellara del Belice, Giarraffa \\
Scenario $\mathrm{V}^{\mathrm{x}}$ & Palermo & Termini Imerese & Ogliarola messinese, Biancolilla \\
Scenario $\mathrm{VI}^{\mathrm{w}}$ & Agrigento & Ribera & Biancolilla, Cerasuola \\
& Foggia & San Servero & Peranzana, Ogliarola \\
\hline
\end{tabular}

Biomonitors of meteorological trends:

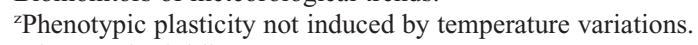

y'Phenotypic rigidity.

'Phenotypic plasticity induced by temperature variations.

wNo trend presence.

particular importance at the time new olive orchards are planted in areas affected by clear climatic changes with temperature and pluviometric regime modifications. In these cases, the use of olive cultivars that show similar behaviors should be considered, either rigid phenological responses (small variations) or synchronous phenological plasticities, avoiding untuning problems among cultivars during flowering phases and therefore limiting causes of autosterility (i.e., "Ogliarola messinese" in Palermo olive orchards and
"Nocellara del Belice" in the nearby area of Trapani present different responses to thermal amounts).

In these applicative fields of research, the flexibility of different genotypes should be considered to avoid the possibility of biological disaster, as is effected for other fruit trees. The indiscriminate transfer of olive cultivars from specific areas to others with different environmental characteristics could deny the same cultivar its decisive role as a determinant factor of the particular pro- duction typically carried out in the original areas. Moreover, from the perspective of modern olive-growing technique, even in countries that are not traditionally olive oil producers, the various international initiatives aimed at protecting biodiversity represent the ideal tool for promoting more sustainable patterns of production.

\section{Literature Cited}

Alcalá, A.R. and D. Barranco. 1992. Prediction of flowering time in olive for the Cordoba olive collection. HortScience 27:1205-1207.

Bonhomme, R. 2000. Bases and limits to using 'degree day' units. Eur. J. Agron. 13:1-10.

Candau, P., F.J. Gonzalez, J. Morales, and C. Tomas. 1998. Forecasting olive (Olea europaea) crop production by monitoring airborne pollen. Aerobiologia 14:185-190.

Emberlin, J., M. Laaidi, M. Detandt, R. Gehrig, S. Jager, D. Myszkowska, N. Nolard, A. RantioLehtimaki, and A. Stach. 2007. Climate change and evolution of the pollen content of the air in seven European countries: The example of birch. Rev. Fr. Allergol. Immunol. Clin. 47: $57-63$.

Estrella, N., A. Menzel, and U. Kramer. 2006. Integration of flowering dates in phenology and pollen counts in aerobiology: Analysis of their spatial and temporal coherence in Germany (1992-1999). Int. J. Biometeorol. 51:49-59.

Fontanazza, G. and L. Baldoni. 1990. Proposta per un programma di miglioramento genetico dell'olivo. Olivae 34:32-39.

Fornaciari, M., F. Orlandi, and B. Romano. 2000. Phenological and aeropalynological survey in an olive orchard in Umbria (central Italy). Grana 39:246-251

Fornaciari, M., F. Orlandi, and B. Romano. 2005. Yield forecasting for olive trees: A new approach in a historical series (Umbria, central Italy). Agron. J. 97:1537-1542.

Galán, C., H. García-Mozo, P. Cariñanos, P. Alcázar, and E. Domínguez. 2001. The role of temperature in the onset of the Olea europaea L. pollen season in south-western Spain. Int. J. Biometeorol. 45:8-12.

Galán, C., L. Vázquez, H. García-Mozo, and E. Domínguez. 2004. Forecasting olive (Olea europaea L.) crop yield based on pollen emission. Field Crops Res. 86:43-51.

Jacoboni, N. and G. Fontanazza. 1981. Le cultivar. L'olivo. REDA, Rome, Italy, pp. 52.

OLEA Databases. 2007. Is a comprehensive olive (Olea europaea L.) science portal established in 2007 by olive researchers in Europe. $<$ http://www.oleadb.it/olivodb.html $>$.

Orlandi, F., B. Romano, and M. Fornaciari. 2005a. Relationship between flowering and Heat Units to analyze crop efficiency of olive cultivars located in southern Italy. HortScience 40:64 68.

Orlandi, F., L. Ruga, B. Romano, and M. Fornaciari. 2005b. Olive flowering as an indicator of local climatic changes. Theor. Appl. Climatol. $81: 169-176$

Orlandi, F., C. Sgromo, T. Bonofiglio, L. Ruga, B. Romano, and M. Fornaciari. 2009. A comparison among olive flowering trends in different Mediterranean areas (south-central Italy) in relation to meteorological variations. Theor. Appl. Climatol. 97:339-347.

Osborne, C.P., I. Chuine, D. Viner, and F.I. Woodward. 2000. Olive phenology as a sensitive indicator of future climatic warming in the 
Mediterranean. Plant Cell Environ. 23:701710.

Pellizzaro, G., D. Spano, A. Canu, and C. Cesaraccio. 1996. Calcolo dei gradi-giorno per la previsione delle fasi fenologiche nell'actinidia. Italus Hortus 3:24-30.

Recio, M., B. Cabezudo, M.M. Trigo, and F.J. Toro. 1996. Olea europaea pollen in the atmosphere of
Malaga (S. Spain) and its relationship with meteorological parameters. Grana 35:308-313. Rodríguez-Rajo, F.J., N. Dacosta, and V. Jato. 2004. Airborne olive pollen in Vigo (northwest Spain): A survey to forecast the onset and daily concentrations of the pollen season. Grana 43:101-110.

Sirois, A. 1998. A brief and biased overview of time series analysis or how to find that evasive trend. WMO report No. 133: WMO/EMEP workshop on advanced statistical methods and their application to air quality data sets; Helsinki; 14-18 Sept. 1998.

Snyder, R.L., D. Spano, C. Cesaraccio, and P. Duce. 1999. Determining degree-day thresholds from field observations. Int. J. Biometeorol. 42:177-182. 